\title{
Frequency and factors associated with inadequate self- care behaviors in patients with type 2 diabetes mellitus in Najran, Saudi Arabia
}

\author{
Based on diabetes self-management questionnaire
}

Awad M. Al-Qahtani, MBBS, MD.

\begin{abstract}
الأهداف : تحديد مدى انتشار وعوامل خطر سلو كيات الرعاية الذاتية السيئة بين

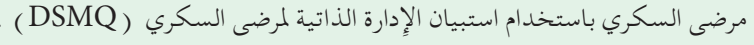
المنهجية : تم إِجراء دراسة مستعرضة على عينة تمثيلية من 355 مريضاً بالسكري

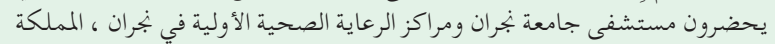

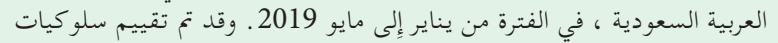

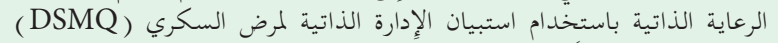

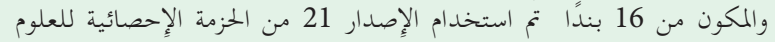

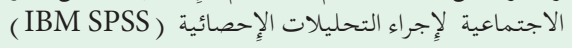

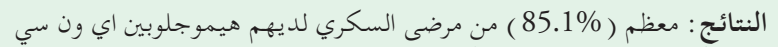

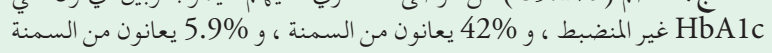

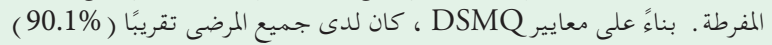

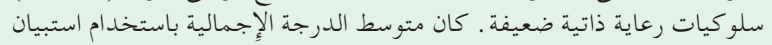

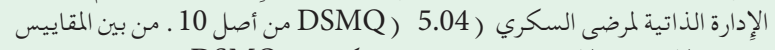

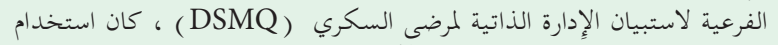

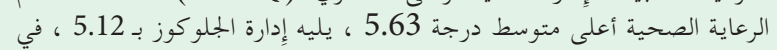

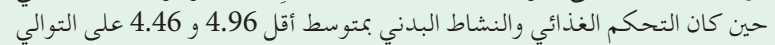

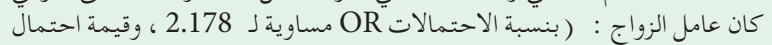

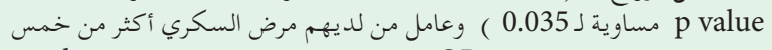

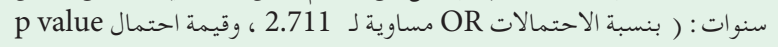

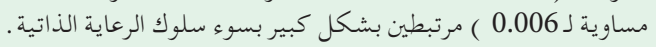

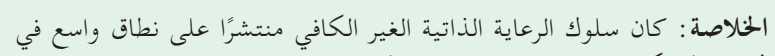

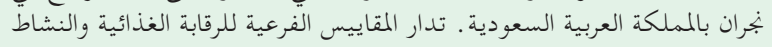

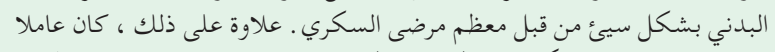

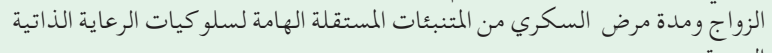

Objectives: To investigate the frequency and factors associated with inadequate self-care behaviors in patients with type 2 diabetes mellitus (T2DM).

Methods: A cross-sectional study was conducted on a sample of 355 patients with T2DM, using multistage cluster sampling, attending the Najran University
Hospital and Primary health care centres in Najran, Saudi Arabia, from January to May 2019. The assessment of self-care behaviors was conducted using the 16-item diabetes self-management questionnaire (DSMQ).

Results: The majority (85.1\%) of the patients with T2DM were uncontrolled, $42 \%$ were obese, and $5.9 \%$ were morbidly obese. Based on DSMQ criteria, the majority of patients $(90.1 \%)$ had poor self-care behaviors. The mean sum of DSMQ was 5.04 out of 10. Among the DSMQ subscales, health care use had the highest mean score of 5.63, followed by glucose management with a score of 5.12, while dietary control had lower mean scores of 4.96 and physical activity had 4.46, all were inadequate. Being married $(\mathrm{OR}=2.178, p=0.035)$ and having $\mathrm{DM}$ for more than 5 years $(\mathrm{OR}=2.711, p<0.006)$ were the significant independent factors associated with poor self-care behavior.

Conclusion: Inadequate self-care behavior is widely prevalent in Najran city, Saudi Arabia. All the DSMQ subscales were poorly managed by most of the diabetic patients. Furthermore, being married and having a longer DM duration are the significant independent factors associated with poor self-care behaviors.

Keywords: diabetes, self-management, questionnaire, prevalence, self-care, behavior

Saudi Med J 2020; Vol. 41 (9): 955-964 doi: 10.15537/smj.2020.9.25339

From the Department of Family and Community Medicine, College of Medicine, Najran University, Najran, Kingdom of Saudi Arabia.

Received 29th April 2020. Accepted 15th August 2020.

Address correspondence and reprint request to: Dr. Awad M. Al-Qahtani, Department of Family and Community Medicine, College of Medicine, Najran University, Najran, Kingdom of Saudi Arabia. E-mail: awadresearch17@gmail.com

ORCID: https://orcid.org/0000-0002-0873-4776 
$\mathrm{D}$ iabetes mellitus (DM) is a pandemic disease that has struck every part of the world. The prevalence of DM in Saudi Arabia in adults is $18.3 \%$, which is one of the highest across the globe. Global prevalence among adults aged $20-79$ years is $9.3 \%$, which amounts to a staggering 463 million people. ${ }^{1}$ With an estimated 7 million people with diabetes and approximately 3 million with pre-diabetes, Saudi Arabia ranks the second highest in the Middle East, and is the seventh in the world for the rate of diabetes. ${ }^{2,3}$ According to the International Diabetes Federation (IDF), as at 2019, the number of patients with diabetes in the Middle East and North Africa (MENA) region was 55 million, which is expected to escalate to 108 million by $2045 .^{3}$ In 2015, the economic burden of diabetes on Saudi Arabia was approximately $\$ 2.4$ billion, an increase of nearly 3 times the level in 2010, and this cost is expected to rise by another $\$ 6.5$ billion in $2020 .{ }^{4}$ The World Health Organization (WHO) has projected that the seventh leading cause of death by 2030 will be diabetes. Diabetes is associated with complications such as diabetic retinopathy, diabetic nephropathy, diabetic neuropathy, macrovascular problems, and limb amputations, which adversely affect the quality of lives of patients. This emphasizes the importance of identifying factors that enhance better prognosis in individuals with diabetes, especially those factors that result in effective regulation of fasting blood glucose levels. ${ }^{5}$

Diabetes self-care behavior eases the burden of caregivers and makes the management of diabetes mellitus easier for the patients and the caregivers as well. ${ }^{6}$ It is important that the procedures adopted in self-care of diabetic patients are effective and reliable. ${ }^{7}$ These interventions pertaining to self-care behaviors are beneficial for doctors and academicians involved in managing patients with diabetes, as well as for studies on new advances for diabetic care. Good glycemic control is hugely associated with self-care behaviors. Self-care practices like regular glucose monitoring, adequate physical activity, healthy food adaptation, and proper medication practices are key factors to improve clinical outcomes of patients with T2DM. Also, the cooperation of family members and physician assistance contributes to the practice of self-care behaviors among patients with T2DM. ${ }^{8}$ Other factors that determine

Disclosure. Authors have no conflict of interests, and the work was not supported or funded by any drug company. diabetes self-care behaviors include diabetes education, duration of disease, presence of comorbid conditions, body mass index (BMI), foot care, and smoking. ${ }^{9}$

A recent study in Madinah by $\mathrm{Al}$ Johani et $\mathrm{a}^{10}$ reported that only $15 \%$ of the participants had good glycemic control, $29 \%$ of participants were incapable of managing their diet, $47 \%$ did not exercise regularly, $85 \%$ did not monitor their blood glucose regularly, $41 \%$ were careless in their foot care, and $25 \%$ had poor compliance for their prescribed medication. They concluded that there is a tremendous scope to improve DM self-care practices in Saudi Arabia and increase the proportion of patients who achieve good glycemic control.

A study in Kuwait by Al-Khaledi ${ }^{11}$ reported that diabetes self-management (DSM), gender, and diabetes complications were significant independent correlates to health-related quality of life. Another study conducted in King Saud Medical City, Riyadh, Saudi Arabia, ${ }^{12}$ revealed positive associations between medication adherence and diabetes knowledge; self-management behaviors (glucose management and healthcare use) and diabetes knowledge; self-management behaviors (dietary control) and fasting blood glucose levels; and age and blood glucose levels (both fasting and HbA1c).

Processes involved in DSM are checking of plasma glucose levels, observation of the legs, and ensuring reduced dietary intake of saturated fat. However, studies have shown very little correlation amongst these procedures. $^{13,14}$ Since DSM involves several activities, there is need to evaluate the components individually, instead of lumping them together. ${ }^{15}$ Self-care is a crucial factor in the establishment of euglycemia in the diabetic state, and for improving prognosis. This is so because inadequate regulation of blood glucose adds significantly to chances of acquiring severe and protracted diabetic complications. Hence, there is need for a standardized evaluation strategy (psychometry) for accurate and reliable analysis of crucial areas which need improvements, from the patients' perspective. ${ }^{16}$

Self-care behaviors are very important factors when it comes to optimizing glycemic control in diabetes. ${ }^{17}$ Proper self-care management, including diet control, regular physical activity, self-monitoring of blood glucose, and adherence to medications, enable patients to manage the disease effectively on their own. ${ }^{18}$

To date, information on the level of self-care behaviors among Saudi Arabian patients with diabetes is limited. Hence, the present study was mainly aimed at investigating inadequate DSM habits amongst patients with T2DM in Najran, Saudi Arabia, and identifying 
the associated factors, using a structured questionnaire (DSMQ).

Methods. This cross-sectional study was carried out among Saudi patients with T2DM, attending the Najran University Hospital (NUH), which is considered a Primary Health Care center, and other Primary Health Care centres (PHCs) in Najran city, Saudi Arabia, from January to May 2019.

All participants were briefed about the study objectives, and a written informed consent obtained from each of them. This study was performed with respect for the rights and personal dignity of the participants. The study was approved by the Scientific Committee of Research, College of Medicine, Najran University. The same ethical approval letter was accepted by the NUH and the PHCs to collect the patients' medical data. The investigation was carried out in conformity with the tenets of Helsinki Declaration.

Target population was all known T2DM patients attending the NUH and PHCs in Najran city, Saudi Arabia, during the period of study. The study included Saudi patients with T2DM, $\geq 18$ years, of both gender, with at least one year duration of diabetes. Pregnant patients, patients with cognitive impairment or debilitating mental illness, or those who did not give consent to take part in the study, were excluded.

Sample size calculation. In reference to the study of Al-Johani et al, ${ }^{10}$ entitled "Self-management practices among type 2 diabetes patients attending primary health-care centres in Medina, Saudi Arabia" which reported a prevalence of poor self-care behavior of $29 \%$. This prevalence was applied to find the optimal sample size. Using the categorical sample size formula of; $N=Z^{2}(\mathrm{pq}) / \mathrm{e}^{2}$, where; $\mathrm{N}=$ sample size; $\mathrm{Z}=$ Confidence level (1.96); $\mathrm{p}=$ estimated proportion of the event (taken from the previous study); $\mathrm{q}=1-\mathrm{p}$; $\mathrm{e}=$ margin of error (0.05), the sample size required to detect a statistically significant result with $95 \%$ levels of confidence and 0.5 margin of error assuming a 2 -tailed statistical test should be 316 , we increased $15 \%$ to the total calculated sample size to cover the non-response rate which totaled 363.

Setting and sampling technique. The study was conducted at NUH and the PHCs in Najran city (each is serving an average of 300 patients with DM). Patients were recruited from family medicine, internal medicine, and endocrinology clinics at NUH as well as from chronic diseases clinics at PHCs (once weekly).

The multi-stage cluster sampling technique was adopted as follows: Stage 1: Stratifying Najran city to different geographical regions (east, west, north, south, and central). Stage 2: List all Primary Health Care Centers (PHCs) in the different regions mentioned above. Stage 3: Selection of one PHC (using the simple random method) from each of the 5 geographical areas. Stage 4: The questionnaires were distributed to all patients with T2DM attending the selected PHCs who met the inclusion criteria, to fill out the questionnaire under the supervision of the medical interns and final year medical students (data collectors) of Najran University College of Medicine. The data collectors filled out the corresponding investigations for each participant's response.

Data collection and study tools. Data was collected by trained medical interns and final year students of Najran University Medical College using the following tools: 1)A researcher-designed questionnaire: The self-reported demographic details of the participants, including age, gender, and educational level were collected using the data collection questionnaire. 2) Diabetes Self-Management Questionnaire (DSMQ) (Appendix 1). The validity and reliability of DSMQ was originally published by Schmitt et al. ${ }^{9}$ Based on their findings, the overall internal consistency of DSMQ was good (0.84). The consistencies of the subscales were deemed acceptable including glucose management (0.77), dietary control (0.77), physical activity (0.76), and health-care use (0.60). ${ }^{9}{ }^{919}$ To measure the reliability and validity of the study questionnaire, a pilot study was conducted among $10 \%$ of the study population. The reliability test for DSMQ which consisted of 16 items was 0.808 Cronbach $\alpha$ or $80.8 \%$, indicating a very good internal consistency of the questionnaire. ${ }^{20}$ The participants included in the pilot study were included in the final data analysis.

Scale distribution and scoring. The DSMQ comprised 4 sub-scales: glucose management (5 items: 1, 4, 6, 10, 12), dietary control (4 items: 2, 5, 9, 13), physical activity ( 3 items; $8,11,15)$ and health-care use (3 items: 3, 7, 14). Each item was designed for patients to self-describe their self-care activity over the past 8 weeks using a 4-point scale (3: applies to me very much, 2: applies to me to a considerable degree; 1 : applies to me to some degree; 0 : does not apply to me). ${ }^{9}$

Data collection. The medical interns and final year students of Najran University Medical College were very well trained to interview and collect the data from the participants, pertaining to DSMQ. As the original version of DSMQ was in English, it had to be translated into the Arabic language, which was carried out by a professional translator. Then, a backtranslation was carried out for the same and compared to the original version by another professional 
translator, which revealed no significant changes. A pilot study was conducted with 15 participants to test the Arabic-version of the DSMQ concerning its cultural appropriateness, comprehension, and ease of use. All the participants said that the questionnaire language was clear and comfortable enough to answer the questions, appropriate culturally, and included most of diabetes self-care practices. The average time needed to complete the questionnaire was 20 minutes. The data collectors gathered the data by interviewing the participants in the triage area of the NUH and the PHCs. The data collectors assisted the study participants to clarify any queries related to the questionnaire. The responses were then transformed into 4 subscale scores and a total sum score (DSMQ score) which ranged from $0-10$, each, with higher score indicating better self-care behavior. ${ }^{9}$ Subsequently, based on the recommendation of Schmitt et al, ${ }^{9}$ the DSMQ scores of the participants were classified as adequate $(>6)$ or inadequate $(\leq 6)$ DSM behaviors.

The questionnaire permits 'sum scale' score and calculation of 4 sub-scale scores. Features of the DSMQ are shown in Appendix 1.

Part of DSMQ scoring included ensuring that adequate self-care was reflected in higher scores. Thus, a transformed score of 10 reflected the best self-assessment score for any DSM. If a patient indicated that a particular option was not needed as part of therapy, the scale score calculation was adapted by deducting 3 points from the theoretical maximum score. Moreover, scale score was not calculated if more than half of the items of a scale were missing.

Record reviewing. The medical data including the information on patients' medical profile, including the most recent glycosylated hemoglobin (HbA1C) level, disease duration, number of medications taken, and number of comorbidities, were obtained from the electronic medical records, after obtaining clearance from the Scientific Committee of Research, College of Medicine, Najran University, and patients' consent. Furthermore, the HbA1C levels were used to categorize the participants into controlled $(<7 \%)$ or uncontrolled $(\geq 7.0 \%)$ T2DM. ${ }^{21}$

Measurements to calculate BMI. Trained personnel recorded the body weight to the nearest $0.1 \mathrm{~kg}$ using a standard beam balance scale with subjects barefoot and wearing light indoor clothing. Body height was recorded to the nearest $0.5 \mathrm{~cm}$. The ratio of body weight to body height squared, expressed as $\mathrm{kg} / \mathrm{m}^{2}$, was defined as BMI. Body mass index was categorized as underweight $\left(<18.5 \mathrm{~kg} / \mathrm{m}^{2}\right)$, normal weight $\left(18.5-24.9 \mathrm{~kg} / \mathrm{m}^{2}\right)$, overweight $\left(25-29.9 \mathrm{~kg} / \mathrm{m}^{2}\right)$, obese $\left(\geq 30 \mathrm{~kg} / \mathrm{m}^{2}\right)$ and morbid obese $\left(\geq 40 \mathrm{~kg} / \mathrm{m}^{2}\right)$ according to the World Health Organization (WHO-BMI) definition. ${ }^{22}$

The following operational definitions were used for the variables of the study: i) Glucose management: This is a major component of living a healthy life with diabetes. Effective glucose management entailed checking and recording blood glucose levels routinely, and taking the diabetes medication as prescribed so as to achieve euglycemic blood glucose levels. (ii) Dietary control simply meant to select foods that make it easy to achieve optimal blood glucose levels. Key elements included vegetables, fruits, and whole grains. Moreover, it included eating in moderate amounts and sticking to regular mealtimes, and strictly following the dietary recommendations given by healthcare professionals. (iii) Physical activity included exercise and incidental activity integrated into daily activity. Being active enhances the sensitivity of the body to insulin, which helps manage diabetes. (iv) Healthcare use was defined as "the timely use of personal health services to achieve the best possible health outcomes". High frequency of health care use is associated with good glycemic control, indicating that availing health care use is crucial for diabetes management.

Statistical analysis. Results of descriptive analysis are presented as numbers and percentages for all qualitative variables, while mean \pm standard and median (min-max) for all quantitative variables. Chi-square test was carried out to determine the factors associated with self-care behavior. Pearson correlation analysis was undertaken to examine the linear relationship between scores of different subscales as well as with DSMQ score. $P$-values of $<0.05$ was chosen as level of significance. All analyses were conducted by a biostatistician utilizing IBM SPSS Statistics for Windows, version 21 (IBM Corp., Armonk, N.Y., USA).

Results. Characteristics of the T2DM patients. The present study surveyed 355 patients with T2DM. Table 1 shows that males were more dominant (63.7\%) and more than half $(51.3 \%)$ were within the age group of 50-64 years. With regard to educational levels, 39.4\% of patients were illiterate or primary educated and $43.9 \%$ attended middle/high schools. Approximately three out of $4(74.9 \%)$ were married, and the majority $(56.3 \%)$ had low monthly income $(<5,000$ SAR). Regarding body mass index (BMI), 38.9\% of the patients were overweight and $47.9 \%$ were obese, of which $5.9 \%$ were morbidly obese. Oral medications were prescribed for $43.9 \%$ of patients, and $27.6 \%$ were taking insulin, while the remaining $28.5 \%$ received both oral medications along with insulin therapy for the management of 
T2DM, and $85.1 \%$ were uncontrolled (HbA1c $\geq 7.0$ ) (mean: $8.4 \pm 4.16$ ). Moreover, $38 \%$ of the patients had DM for $1-5$ years, $34.6 \%$ had DM for 6-10 years, while $20.8 \%$ had it for $11-20$ years (Table 1 ).

Diabetes self-management as measured by the DSMQ. The descriptive statistics of DSMQ and its subscales are shown in Table 2. The mean total DSMQ

Table 1 - Characteristics of patients with type 2 diabetes mellitus (T2DM), Najran, KSA, 2019 (N=355).

\begin{tabular}{|c|c|}
\hline Study variables & n $\quad(\%)$ \\
\hline \multicolumn{2}{|l|}{ Age group (years) } \\
\hline $18-34$ & $45(12.7)$ \\
\hline $35-49$ & $80(22.5)$ \\
\hline $50-64$ & $182(51.3)$ \\
\hline$\geq 65$ & $48(13.5)$ \\
\hline \multicolumn{2}{|l|}{ Gender } \\
\hline Male & $226(63.7)$ \\
\hline Female & $129(36.3)$ \\
\hline \multicolumn{2}{|l|}{ Educational level } \\
\hline Illiterate/Primary school & $140(39.5)$ \\
\hline Middle/Secondary School & $156(43.9)$ \\
\hline University or higher & $59(16.6)$ \\
\hline \multicolumn{2}{|l|}{ Marital status } \\
\hline Unmarried & $89(25.1)$ \\
\hline Married & $266(74.9)$ \\
\hline \multicolumn{2}{|l|}{ Monthly income (SAR) } \\
\hline$<5,000$ & $200(56.3)$ \\
\hline $5,000-10,000$ & $116(32.7)$ \\
\hline$>10,000$ & $39(11.0)$ \\
\hline \multicolumn{2}{|l|}{ Body mass index level } \\
\hline Normal & $47(13.2)$ \\
\hline Overweight & $138(38.9)$ \\
\hline Obese & $170(47.9)$ \\
\hline \multicolumn{2}{|l|}{ Current medication } \\
\hline Insulin & $98(27.6)$ \\
\hline Oral & $156(43.9)$ \\
\hline Both & $101(28.5)$ \\
\hline \multicolumn{2}{|c|}{ Glycemic control status (HbA1c\%) } \\
\hline $\mathrm{HbA1c}($ mean $\pm \mathrm{SD})$ & $8.4 \pm 4.16$ \\
\hline Controlled $(<7.0)$ & $53(14.9)$ \\
\hline Uncontrolled $(\geq 7.0)$ & $302(85.1)$ \\
\hline \multicolumn{2}{|l|}{ Duration of diabetes (years) } \\
\hline $1-5$ & $135(38.0)$ \\
\hline $6-10$ & $123(34.6)$ \\
\hline $11-20$ & $74(20.9)$ \\
\hline$>20$ & $23 \quad(6.5)$ \\
\hline
\end{tabular}

score was $5.04 \pm 0.86$ out of 10 . Among the subscales, healthcare use had the highest mean score of $5.63 \pm$ 1.35 , followed by glucose management $(5.12 \pm 1.36)$, dietary control $(4.96 \pm 1.40)$, and physical activity $(4.46 \pm 1.68)$.

Figure 1 revealed that the majority $(90.1 \%)$ of patients with T2DM were classified as having an inadequate self-behavior. In addition, the frequency of patients with inadequate glucose management was $87.3 \%$, dietary control $86.5 \%$, physical activity $78.3 \%$, and healthcare $62 \%$.

Table 3 depicts the correlation (Pearson's r) between DSMQ and its subscales. The results revealed that glucose management had positive significant $(p<0.001)$ correlation with dietary control $(\mathrm{r}=0.304)$, healthcare use $(\mathrm{r}=0.203)$, and total DSMQ $(\mathrm{r}=0.640)$ but inversely correlated with DM duration $(\mathrm{r}=-0.112 ; p=0.035)$. We also observed significant $(p<0.001)$ correlation between dietary control and healthcare use $(\mathrm{r}=0.226)$ and total DSMQ ( $\mathrm{r}=0.602)$, but inversely correlated with age $(\mathrm{r}=-0.194 ; p<0.001)$ and DM duration $(\mathrm{r}=-0.119$; $p=0.025)$. Furthermore, the correlation was positively statistically significant between physical activity and total DSMQ $(\mathrm{r}=0.533 ; p<0.001)$, age $(\mathrm{r}=0.140$;

Table 2 - Descriptive statistics of diabetes self-management questionnaire (DSMQ) domains among patients with type 2 diabetes mellitus (T2DM), Najran, KSA, 2019 ( $\mathrm{n}=355)$.

\begin{tabular}{|c|c|c|c|}
\hline $\begin{array}{l}\text { DSMQ } \\
\text { subscales }\end{array}$ & $\begin{array}{l}\text { Frequency } \\
\mathbf{n}(\%)\end{array}$ & $\begin{array}{l}\text { Total score }(10) \\
\text { mean } \pm S D\end{array}$ & $\begin{array}{c}\text { Median } \\
\text { (1st - 3rd quartile) }\end{array}$ \\
\hline \multicolumn{2}{|c|}{ Glucose management } & $5.12 \pm 1.36$ & $5.33(1.33-10.0)$ \\
\hline Adequate & $45(12.7)$ & & \\
\hline Inadequate & $310(87.3)$ & & \\
\hline \multicolumn{2}{|l|}{ Dietary control } & $4.96 \pm 1.40$ & $5.00(0-9.17)$ \\
\hline Adequate & $48(13.5)$ & & \\
\hline Inadequate & $307(86.5)$ & & \\
\hline \multicolumn{2}{|l|}{ Physical activity } & $4.46 \pm 1.68$ & $4.44(0-8.89)$ \\
\hline Adequate & $77(21.7)$ & & \\
\hline Inadequate & $278(78.3)$ & & \\
\hline \multicolumn{2}{|l|}{ Healthcare use } & $5.63 \pm 1.35$ & $5.56(0-10.0)$ \\
\hline Adequate & $135(38.0)$ & & \\
\hline Inadequate & $220(62.0)$ & & \\
\hline \multicolumn{2}{|c|}{ Self-care behavior sum-scale } & $5.04 \pm 0.86$ & $5.03(2.47-8.58)$ \\
\hline Adequate & $35(09.9)$ & & \\
\hline Inadequate & $320(90.1)$ & & \\
\hline
\end{tabular}


Table 3 - Correlation between diabetes self-management domains among patients with type 2 diabetes mellitus (T2DM), Najran, KSA, 2019 ( $\mathrm{n}=355$ ).

\begin{tabular}{llcccccc}
\hline SN & DSMQ subscales & I & II & III & IV & V & VI \\
\hline I & Glucose management & 1 & & & & & \\
II & Dietary control & 0.304 & 1 & & & & \\
III & Physical activity & 0.078 & -0.036 & 1 & & & \\
IV & Healthcare use & $0.203^{*}$ & $0.226^{*}$ & 0.065 & 1 & & \\
V & Total DSMQ & $0.640^{*}$ & $0.602^{*}$ & $0.533^{*}$ & $0.601^{*}$ & 1 & \\
VI & Age & -0.055 & $-0.194^{*}$ & $0.140^{*}$ & 0.046 & -0.014 & 1 \\
VII & DM duration & $-0.112^{\dagger}$ & $-0.119^{\dagger}$ & $0.129^{\dagger}$ & $-0.111^{\dagger}$ & -0.074 & $0.360^{*}$ \\
\hline
\end{tabular}

${ }^{*}$ Correlation was statistically significant at $\mathrm{p}<0.01$ level (2-tailed). ${ }^{\dagger}$ Correlation was statistically significant at $p<0.05$ level (2-tailed). DM: diabetes mellitus, DSMQ: diabetes self-management questionnaire

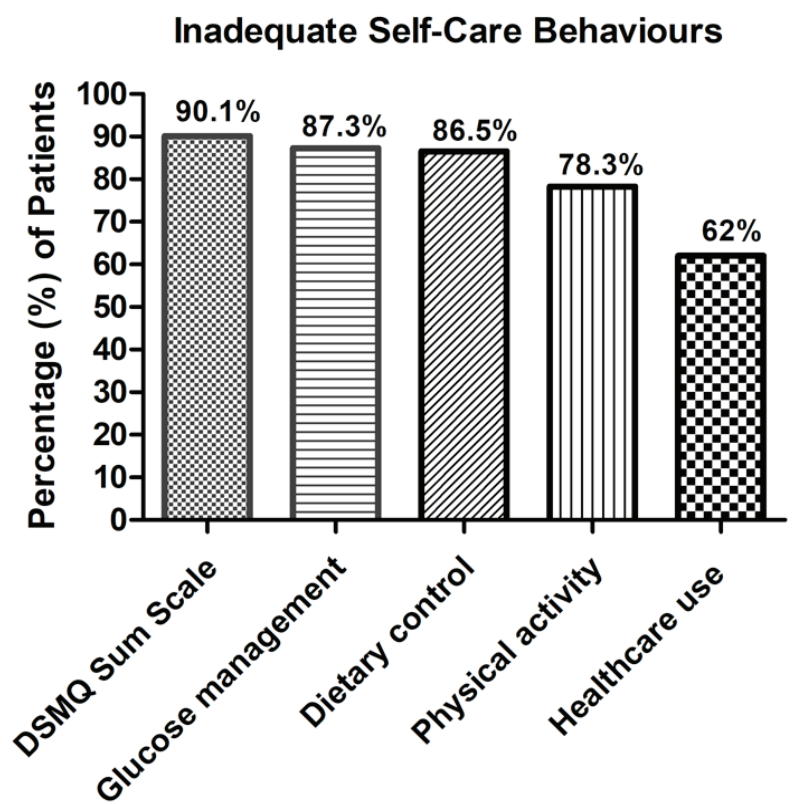

Figure 1 - Classification of Diabetes self-care behavior according to diabetes self-management questionnaire, Najran, KSA, 2019.

$p=0.008)$, and DM duration ( $\mathrm{r}=0.129 ; p=0.015)$ while healthcare use was positively significantly $(p<0.001)$ correlated with total DSMQ $(\mathrm{r}=0.601)$; however, it was inversely correlated with DM duration $(\mathrm{r}=-0.111$; $p=0.036$ ). Finally, age showed positive significant $(p<0.001)$ correlation with DM duration $(\mathrm{r}=0.360)$.

Factors associated with inadequate self-care behavior. Results from investigating the factors associated with poor self-care behavior (Table 4) revealed that married patients were 2 times higher to have poor self-care behavior compared to unmarried patients $(\mathrm{OR}=2.178$, $p=0.035$ ). It was also found out that patients with more than 5 years of DM duration were more associated with inadequate self-care behavior, and the likelihood was 2.7 times higher compared to those with $\leq 5$ years $(p=0.006)$. Other variables included in the analysis, age group in years, gender, educational level, monthly income, $\mathrm{BMI}$, current medication, most recent $\mathrm{HbA1c}$ level and a number of comorbidities were not significantly associated with inadequate self-care behavior (Table 4).

Discussion. This study highlights the levels and factors associated with inadequate self-care behaviors among Saudi patients with T2DM. The results obtained indicate that majority of the population in Najran has inadequate self-care behavior in the management of diabetes, with a rate of $90.1 \%$. Besides, the participants showed poor self-care behavior in different domains of DSMQ with inadequate glucose management (87.3\%), dietary control $(86.5 \%)$, physical activity $(78.3 \%)$, and healthcare use $(62 \%)$. This is consistent with the findings of Alrahbi, ${ }^{20}$ who used a Diabetes Self-Management Scale (DSMS) of 60 items examining more domains, reported that diabetes self-management was inadequate among the patients with T2DM, with only $1 \%$ of them doing regular self-monitoring of blood glucose, and only $18 \%$ of them had healthy dietary control. The results also corroborate those of Nejaddadgar et al, ${ }^{23}$ (63.6\%), and Totesora et al, ${ }^{24}(51.5 \%)$ of patients, had a low score on self-care; however, the rate of inadequate DSM was much higher $(90.1 \%)$ in the current study. However, the results are contrary to the findings of Ang et al, ${ }^{25}$ which showed that inadequate self-care behavior was seen in only $15.5 \%$ of patients with T2DM.

In assessing the DSMQ and its subscales as suggested by Schmitt et al, ${ }^{9}$ study patients with T2DM in Najran appeared to manifest lower mean scores in all the subscales with physical activity $(4.46 \pm 1.68)$, dietary control, (4.96 \pm 1.40$)$, glucose management (5.12 \pm 
1.36), and with a marginally better mean observed in health care use $(5.63 \pm 1.35)$. In particular, the mean scores for physical activity and diet control were less than the other 2 subscales, which is consistent with the previous findings of Ang et $\mathrm{al} ;^{25}$ however, Ang et $\mathrm{a}^{25}$ observed that the mean score for all the subscales were much higher compared to the present study. The low mean score for different domains of DSMQ suggest that lack of physical activity, poor diet control, glucose management, and health care use in patients with

Table 4 - Diabetes self-care behavior in association with some factors among patients with type 2 diabetes mellitus (T2DM), Najran, KSA, $2019(n=355)$.

\begin{tabular}{|c|c|c|c|c|c|}
\hline \multirow[t]{2}{*}{ Factor } & \multicolumn{2}{|c|}{ Self-care behaviors (\%) } & \multirow[t]{2}{*}{ OR } & \multirow{2}{*}{$\begin{array}{l}95 \% \text { confidence } \\
\text { interval }\end{array}$} & \multirow[t]{2}{*}{$P$-value } \\
\hline & $\begin{array}{c}\text { Inadequate } \\
(n=320)\end{array}$ & $\begin{array}{l}\text { Adequate } \\
(\mathbf{n}=35)\end{array}$ & & & \\
\hline \multicolumn{6}{|l|}{ Personal factors } \\
\hline \multicolumn{6}{|l|}{ Age group (years) } \\
\hline $18-34$ & $43(13.4)$ & $02(05.7)$ & Ref & & \\
\hline $35-49$ & $76(23.8)$ & $04(11.4)$ & 0.512 & $0.089-2.940$ & 0.453 \\
\hline $50-64$ & $157(49)$ & $25(71.5)$ & 0.579 & $0.138-2.431$ & 0.455 \\
\hline$\geq 65$ & $44(13.8)$ & $04(11.4)$ & 1.752 & $0.579-5.300$ & 0.321 \\
\hline \multicolumn{6}{|l|}{ Gender } \\
\hline Male & $204(63.8)$ & $22(62.9)$ & Ref & & \\
\hline Female & $116(36.2)$ & $13(37.1)$ & 0.962 & $0.467-1.982$ & 0.917 \\
\hline \multicolumn{6}{|l|}{ Educational level } \\
\hline Primary or illiterate & $121(37.8)$ & $19(54.3)$ & Ref & & \\
\hline Secondary or Intermediate & $146(45.6)$ & $10(28.6)$ & 1.387 & $0.524-3.670$ & 0.510 \\
\hline University or higher & $53(16.6)$ & $06(17.1)$ & 0.605 & $0.210-1.746$ & 0.353 \\
\hline \multicolumn{6}{|l|}{ Marital status } \\
\hline Unmarried & $75(23.4)$ & $14(40.0)$ & Ref & & \\
\hline Married & $245(76.6)$ & $21(60.0)$ & 2.178 & $1.056-4.492$ & $0.035^{* *}$ \\
\hline \multicolumn{6}{|l|}{ Monthly income (SAR) } \\
\hline$<5,000$ & $180(56.3)$ & $20(57.1)$ & Ref & & \\
\hline $5,000-10,000$ & $104(32.5)$ & $12(34.3)$ & 1.333 & $0.376-4.725$ & 0.656 \\
\hline$>10,000$ & $36(11.3)$ & 03 (08.6) & 1.385 & $0.370-5.187$ & 0.629 \\
\hline \multicolumn{6}{|l|}{ Medical factors } \\
\hline \multicolumn{6}{|l|}{ Body mass index level } \\
\hline Normal & $44(13.8)$ & $03(08.6)$ & Ref & & \\
\hline Overweight & $126(39.4)$ & $12(34.3)$ & 0.511 & $0.145-1.801$ & 0.297 \\
\hline Obese & $150(46.9)$ & $20(57.1)$ & 0.714 & $0.336-1.518$ & 0.382 \\
\hline \multicolumn{6}{|l|}{ Current medication } \\
\hline Insulin & $92(28.7)$ & $06(17.1)$ & Ref & & \\
\hline Oral & $141(44.1)$ & $15(42.9)$ & 0.405 & $0.149-1.102$ & 0.077 \\
\hline Both & $87(27.2)$ & $14(40.0)$ & 0.661 & $0.304-1.436$ & 0.296 \\
\hline \multicolumn{6}{|l|}{ Duration of diabetes (years) } \\
\hline$\leq 5$ & $114(35.6)$ & $21(60.0)$ & Ref & & $0.006^{* *}$ \\
\hline$>5$ & $206(64.4)$ & $14(40.0)$ & 2.711 & $1.327-5.535$ & \\
\hline \multicolumn{6}{|l|}{ Most recent HbA1c level (\%) } \\
\hline$<7.0$ & $50(15.6)$ & 03 (08.6) & Ref & & \\
\hline$\geq 7.0$ & $270(84.4)$ & $32(91.4)$ & 0.506 & $0.149-1.717$ & 0.275 \\
\hline \multicolumn{6}{|l|}{ Number of comorbidities } \\
\hline 0 & $88(27.5)$ & $16(45.7)$ & Ref & & \\
\hline 1 & $88(27.5)$ & $06(17.1)$ & 2.655 & $0.928-7.594$ & 0.069 \\
\hline 2 & $71(22.2)$ & 08 (22.9) & 0.995 & $0.292-3.394$ & 0.994 \\
\hline$\geq 3$ & $73(22.8)$ & $05(14.3)$ & 1.645 & $0.514-5.269$ & 0.402 \\
\hline
\end{tabular}


T2DM are significant challenges in the management of diabetes in Saudi Arabia. On the other hand, in Iran, ${ }^{23}$ researchers who used Summary of Diabetes Self-Care Activities Questionnaire (SDSCA: uses a different scale than DSMQ), reported conflicting results: they found that the lowest DSM scores were linked to testing blood glucose, regularity in drug use, and physical exertion, while optimum mean scores were obtained in health diet and foot care.

In the present study, the overall mean DSMQ score was also classified as sub-optimal $(5.04 \pm 0.86)$. It was noticed that, compared with another study, the measured self-care behavior using DSMQ in Malaysia ${ }^{25}$ (DSMQ "Sum Scale" 7.48), the findings in the present study showed a lower mean score in DSMQ and its subscales. Whereas, a study by Bukhsh et $\mathrm{al}^{26}$ reported a lower DSMQ "Sum Scale" (3.96) compared to the present study. Another study conducted in USA, ${ }^{27}$ but among food insecure people with diabetes using DSMQ reported "Sum Scale" (6.47). In the present study, being married and having a prolonged duration of diabetes were significantly linked with inadequate self-care behavior, and the likelihood ratio was 2.1 times and 2.7 times higher, respectively. The current study also revealed that glucose management was positively correlated with dietary control, healthcare use and total DSMQ score; dietary control was positively correlated with healthcare use and total DSMQ score and inversely correlated with age and DM duration; physical activity was positively correlated with total DSMQ score, age, and duration of DM; healthcare use was positively correlated with total DSMQ score and inversely with DM duration. Previous studies provide conflicting reports with regard to factors related to self-care behaviors. Al Shayban, ${ }^{28}$ observed that age ( $>60$ years) $(0.01)$, higher education (0.03), and working status (0.012) revealed statistical significance in dietary control. Obesity statistically correlated with using health care use, it indicates that obese patients were less likely to use health care services. And insulin therapy showed a significant relationship with glucose management, suggesting that patients who used insulin alone or in combination with oral medicines had optimal glucose management than patients who received only oral medications. A study conducted by Kakade et $\mathrm{al}^{29}$ revealed statistically significant differences between glycemic control in relation with diabetes self-care practices (glucose management $[p=0.003]$, dietary control $[p=0.006]$, and sum scale $[p=0.028])$.

Alrahbi et $\mathrm{al}^{18}$ reported that there was no significant relationship between DSM and glycemic control, but DSM was correlated with educational status, age, gender, and duration of DM. In the current study, there was no significant correlation between total DSMQ score and glycemic control, despite the fact that majority of the patients had poor glycemic control, asserting that a study with a longer duration and with a larger and more representative sample was needed to demonstrate significant correlation between total DSMQ score and glycemic control. However, in this study, total DSMQ score was significantly correlated with glucose management, dietary control, physical activity, and healthcare use. The contrasting results pertaining to self-care behaviors observed in different countries could be influenced by the socioeconomic and cultural differences of these countries.

In the current study, $85.1 \%$ of patients with T2DM had poor control of blood glucose which is in line with the findings of Alrahbi, ${ }^{20}$ who reported about $70 \%$ of the patients had poor glycemic control with $\mathrm{HbA1c}$ values above 7 . The mean $\mathrm{HbA1c}$ value observed in the current study was $8.4 \pm 4.16$, which is similar to the findings of Alrahbi, ${ }^{20}$ who reported the mean $\mathrm{HbAlc}$ value of $8.4 \pm 2.12$. Another study by Totesora et al, ${ }^{24}$ observed that $66 \%$ of patients with T2DM had poor glycemic control, and that diabetes self-care and glycemic outcomes had a significant association. Similar studies, in Pakistan ${ }^{26}$ reported 83\% and India, ${ }^{29} 91.8 \%$ of patients with T2DM, did not have adequate control of blood glucose. Whereas, another study by Ang et al, ${ }^{25}$ showed poor adherence to glycemic control (55.3\%), which is lower compared to the findings of the present study, with poor glycemic control observed in $85.1 \%$ of participants.

Various factors may contribute to the inadequate diabetes self-management in patients with T2DM from Najran. For example, absence of adequate enlightenment on DSM may be one of the reasons for poor DSM, since health education on diabetes care is lacking in Saudi Arabia. The challenges facing diabetes self-care in Saudi Arabia include lack of specially trained personnel to provide psychological support and counselling for patients with diabetes, lack of knowledge on diabetes, ignorance and wrong beliefs (namely, only a health care professional can administer insulin and monitor blood glucose levels; diabetics cannot lead a normal social life), food and dietary factors (namely, non-healthy eating habits), and gender-related problems (namely, multiple pregnancies in women, restricted access to sport activities and Gymnasiums due to cultural barriers). ${ }^{30}$

Ang et $\mathrm{al}^{25}$ observed that inadequate self-care behaviors were significantly associated with the disease duration, with poor DSM behaviors observed in patients with disease duration between 6 to 10 years. In this 
study, long history of DM ( $>5$ years) was significantly associated with having inadequate self-care behavior. This finding could be attributed to lack of patient motivation, and activation in patients with longer duration of $\mathrm{DM},{ }^{31}$ which is needed to assist patients in changing their self-care behaviors, another likely reason is lack of diabetes self-management education, which has an essential role in providing fundamental knowledge and skills for people with T2DM to help them in adopting recommended behaviors such as healthy diets, physical exercise, blood glucose monitoring, foot-care, and the administration of medicines. ${ }^{32}$ Another vital factor negatively affecting the level of patient care is the negligence of patients to attend scheduled clinical appointments. ${ }^{33}$ In Najran, Saudi Arabia, there is no public transportation, and patients need to use a car or taxi to visit the diabetic clinics. A study in Saudi Arabia observed that the demographic factors linked to missed appointments among Saudi patients included longdistance travel and the unavailability of transportation. ${ }^{34}$ Several excuses are presented by absentee patients, including logistical problems concerning travel and related expenses. However, other studies have reported that patients who had DM for longer duration were very efficient and confident in DSM. Such patients may have developed smart strategies for better DSM, relative to their counterparts with fewer years of DM. In addition, it is likely that they might have experienced complications which propelled them to better self-care behaviors. ${ }^{35,36}$

Another key finding worth mentioning is that married patients were significantly associated with poor self-care behaviors, since the presence of family translates to increased responsibilities like daily chores, kids education, could lead to reduced time for personal care, especially related to diabetes self-care. However, these findings are in contrast to that of Eid et al, ${ }^{37}$ who reported that marital status had a positive impact on self-care behaviors, since it is assumed that the presence of a partner enhances positive attitudes towards care of one's health, and the patient/companion alliance should be recognized in therapeutic planning.

The results of this investigation underscore the imperative need to ensure adequate diabetes self-care behavior among patients with T2DM. Continuous efforts should be made by health care professionals to determine precisely how an individual can meet the recommended lifestyle modifications, and to intensify education on self-care, particularly among those patients who have a longer duration of DM, are married, have poor glycemic control, obesity and comorbidities.
Study limitations. The current study was carried out in a single city, which cannot represent the whole Saudi population. Apart from that, the assessment of self-care behaviors was based solely on self-reporting by the participants. Thus, the data could be affected by bias arising from over-reporting or under-reporting.

In conclusion, poor self-care behavior is widely prevalent among patients with T2DM in Najran, Saudi Arabia. All subscales were inadequately managed by the majority of the participants. Furthermore, being married and being with longer DM duration are significantly associated with inadequate self-care behavior. The findings of this research are significant and will help to bridge the gap in knowledge about diabetes patients in Saudi Arabia, and might improve the future implementation of diabetes self-management programs.

Clinicians and other healthcare professionals like pharmacists should take up positive roles in providing education and training on both medication and lifestyle issues to patients with T2DM, to have a positive impact on health outcomes of diabetic patients by improving their self-care practices. Multifaceted interventions by health care agencies and educational institutions that include affective strategies to address psychosocial issues, individual and community factors which include community infrastructure, support within the family, eating disorders will optimize the self-care behavior.

Acknowledgment. We would like to thank Medical Science Editors (https://www.medscienceeditors.com) for English language editing.

\section{References}

1. International Diabetes Federation Prevalence of diabetes in Saudi Arabia. [cited 2020 March 5]. Available from: https:// idf.org/our-network/regions-members/middle-east-and-northafrica/members/46-saudi-arabia.html

2. World Health Organization. WHO mortality database. Geneva (SW): World Health Organization; 2016. Available from: https://apps.who.int/healthinfo/statistics/mortality/whodpms/

3. International Diabetes Federation. IDF Diabetes Atlas, 9th ed. [cited 2019]. Available from: https://www.diabetesatlas.org

4. Alhowaish AK. Economic costs of diabetes in Saudi Arabia. J Family Community Med 2013; 20: 1-7.

5. Ishak NH, Mohd Yusoff SS, Rahman RA, Kadir AA. Diabetes self-care and its associated factors among elderly diabetes in primary care. J Taibah Univ Med Sc 2017; 12: 504-511.

6. Ahmed Z, Yeasmeen F. Active family participation in diabetes self-care: a commentary. Diabetes Manag 2016; 6: 104-107.

7. Schmitt A, Reimer A, Hermanns N, Huber J, Ehrmann D, Schall S, et al. Assessing diabetes self-management with the diabetes self-management questionnaire (DSMQ) can help analyse behavioural problems related to reduced glycaemic control. PLoS One 2016; 11: e0150774. 
8. Tiruneh SA, Ayele AA, Emiru YK, Tegegn HG, Ayele BA, Engidaw MT, et al. Factors influencing diabetes self-care practice among type 2 diabetes patients attending diabetic care follow up at an Ethiopian General Hospital, 2018. J Diabetes Metab Disord 2019; 18: 199-206.

9. Schmitt A, Gahr A, Hermanns N, Kulzer B, Huber J, Haak T. The Diabetes Self-Management Questionnaire (DSMQ): development and evaluation of an instrument to assess diabetes self-care activities associated with glycaemic control. Health Qual Life Outcomes 2013; 11: 138.

10. Al Johani KA, Kendall GE, Snider PD. Self-management practices among type 2 diabetes patients attending primary health-care centres in Medina, Saudi Arabia. East Mediterr Health J 2015; 21: 621-628.

11. Al-Khaledi M, Al-Dousari H, Al-Dhufairi S, Al-Mousawi T, Al-Azemi R, Al-Azimi F, et al. Diabetes self-management: a key to better health-related quality of life in patients with diabetes. Med Princ Pract 2018; 27: 323-331.

12. AlShareef SM, AlWabel AA, AlKhathlan MA, AlKhazi AA, AlMaarik AK, AlGarni AM, et al. Glycemic control in diabetic patients in Saudi Arabia: The role of knowledge and selfmanagement - A cross-sectional study. Glob J Health Sci 2017; 9: $25-31$.

13. Alvarado-Martel D, Fernandez MA, Vigaray MC, Carrillo A, Boronat M, Montesdeoca AE, et al. Identification of psychological factors associated with adherence to self-care behaviors amongst patients with type 1 diabetes. J Diabetes Res 2019; 2019: 6271591.

14. Bukhsh A, Lee SWH, Pusparajah P, Schmitt A, Khan TM. Psychometric properties of the Diabetes Self-Management Questionnaire (DSMQ) in Urdu. Health Qual Life Outcomes 2017; 15: 200.

15. Hilliard ME, Powell PW, Anderson BJ. Evidence-based behavioral interventions to promote diabetes management in children, adolescents, and families. Am Psychol 2016; 71 : 590-601.

16. Schmitt A, Reimer A, Hermanns N, Huber J, Ehrmann D, Schall S, et al. Assessing Diabetes Self-Management with the Diabetes Self-Management Questionnaire (DSMQ) can help analyse behavioural problems related to reduced glycaemic control. PLoS One 2016; 11: e0150774.

17. Bukhsh A, Khan TM, Nawaz MS, Ahmed HS, Chan KG, Lee $\mathrm{LH}$, et al. Association of diabetes-related self-care activities with glycemic control of patients with type 2 diabetes in Pakistan. Patient Prefer Adherence 2018; 12: 2377-2385.

18. American Diabetes Association. Standards of medical care in diabetes-2016. Abridged for primary care providers. Clin Diabetes 2016; 34: 3-21.

19. Schmitt A, Hermanns N, Kulzer B, Reimer A, Schall S, Haak T. The Diabetes Self-Management Questionnaire (DSMQ) can detect inadequate self-care behaviour and help identify patients at risk of a negative diabetes prognosis. 50th EASD Annual Meeting; 2014 Sep 15-19; Vienna, Austria. Diabetologia 2014; 57 (Suppl 1): 1041.

20. Alrahbi H. Diabetes self-management (DSM) in Omani with type-2 diabetes. Int J Nur Sci 2014; 1: 352-359.

21. American Diabetes Association (ADA) Standards of Medical Care in Diabetes-2020. Diabetes Care 2020; 43 (Supplement 1): S1-S2.

22. World Health Organization. Obesity: preventing and managing the global epidemic. Report of a WHO consultation on obesity. Geneva (SW): World Health Organization; 2000. p. 1-253.
23. Nejaddadgar N, Solhi $M$, Jegarghosheh S, Abolfathi $M$, Ashtarian H. Self-care and related factors in patients with type 2 diabetes. Asian J Biomed Pharm Sci 2017; 7: 6-10.

24. Totesora D, Ramos-Rivera MI, Villegas-Florencio MQ, Reyes-Sia PN. Association of Diabetes-related emotional distress with diabetes self-care and glycemic control among adult patients with type 2 diabetes at a tertiary hospital in Manila, Philippines. J ASEAN Fed Endocr Soc 2019; 34: 189-196.

25. Ang JY, Leo JS, George D, Chan HK. Inadequate Self-Care Behaviors among Malaysian Diabetic Patients: The Need for Action by Hospital Pharmacists. J Pharm Pract Community Med 2018; 4: 51-54.

26. Bukhsh A, Khan TM, Nawaz MS, Ahmed HS, Chan KG, Goh BH. Association of diabetes knowledge with glycemic control and self-care practices among Pakistani people with type 2 diabetes mellitus. Diabetes Metab Syndr Obes 2019; 12: 1409-1417.

27. Wade T, Fahey O, Vanmieghem M, Vivian E. Self-care behaviours of food-insecure persons with diabetes. Health Edu Care 2019; 4: 1-4.

28. Al-Shayban DM. Using the Diabetes Self-Management Questionnaire (DSMQ) to assess diabetes self-care activities for diabetes patients in King Fahad University Hospital-Saudi Arabia. Value in Health 2017; 20: A482-A483.

29. Kakade AA, Mohanty IR, Rai S. Assessment of factors associated with poor glycemic control among patients with type II diabetes mellitus. Integr Obes Diabetes 2018; 4: 1-6.

30. Almutairi KM. Quality of diabetes management in Saudi Arabia: a review of existing barriers. Arch Iran Med 2015; 18 : 816-821.

31. Edelman SV. Taking control of your diabetes: An innovative approach to improving diabetes care through educating, motivating, and making the connection between patients and health care providers. Clin Diabetes 2017; 35: 333-339.

32. Department of Health Survey UK. Supporting people with long-term conditions to self-care: A guide to developing local strategies and good practice. [cited 2006]. Available from: http:// webarchive.nationalarchives.gov.uk/20130107105354/http:/ www.dh.gov.uk/prod_consum_dh/groups/dh_digitalassets/@ dh/@en/documents/digitalasset/dh_4130868.pdf

33. Williamson AE, Ellis DA, Wilson P, McQueenie R, McConnachie A. Understanding repeated non-attendance in health services: a pilot analysis of administrative data and full study protocol for a national retrospective cohort. BMJ Open 2017; 7: e014120.

34. Al-Hamad Z. Reasons for missing appointments in general clinics of primary health care centre in Riyadh military hospital, Saudi Arabia. Int J Med Sci Public Health 2013; 2: 258-267.

35. Adu MD, Malabu UH, Malau-Aduli AEO, Malau-Aduli BS. Enablers and barriers to effective diabetes self-management: A multi-national investigation. PLoS One 2019; 14: e0217771.

36. Jackson IL, Adibe MO, Okonta MJ, Ukwe CV. Knowledge of self-care among type 2 diabetes patients in two states of Nigeria. Pharmacy Practice 2014; 12: 404.

37. Eid LP, Leopoldino SAD, Ollerm GASAO, Pompero DA, Martins MA, Gueroni LPB. Factors related to self-care activities of patients with type 2 diabetes mellitus. Esc Anna Nery 2018; 22: e20180046. 